\title{
Wealth Constraints, Migrant Selection, and Inequality in Developing Countries
}

\author{
Joaquín Naval * \\ Departament d'Economia, Universitat de Girona, Spain
}

June 18, 2015

\begin{abstract}
Migration and remittances may increase the wealth of an economy but can also increase economic inequality. This paper builds a theoretical framework that relates migration and education decisions to liquidity constraints in migrants' home countries. The evolution of technology together with migration costs determines the effects of migration on education, income and wealth inequality in labor-exporting developing countries. The model predicts that in the first stages of technological development migration rates increase and migration enlarges economic inequality over time for high migration costs. At more advanced stages of development or low migration costs, migration rates and wealth inequality decline over time. The technological gap and migration costs determine the effects of migration on inequality. Wealth constraints play a crucial role in selection and inequality.
\end{abstract}

Keywords: inequality, migration, remittances, education.

JEL Classification: F22, F24, F62, O15.

*I would like to thank my supervisor Jordi Caballé, and Jesús Fernández-Huertas for his useful comments and directions. I also wish to thank Frédéric Docquier, David de la Croix, Joel López Real, and Nuria Rodríguez for valuable suggestions. This paper has benefited from discussions at seminars in the ENTER jamboree at Tilburg University, the Doctoral Meeting of Montpellier, the Doctoral Workshop at Université Catholique de Louvain, and the Summer School in Public Economics: Immigration and Public Policy in the Institut d'Economia de Barcelona. Financial support from the Spanish Ministry of Education and Science, through grant SEJ2006-00369. All remaining errors are my own. E-mail: joaquin.naval@udg.edu. 


\section{Introduction}

International labor flows arise as a consequence of the globalization process. As a matter of fact, labor movements affect both emigration and immigration countries. There can be changes in the labor supply, skill composition, wages and investment flows, among other outcomes. In this work, we discuss some effects of these movements on labor-exporting countries. These countries experience a reduction in their labor supply and an increase in capital flows due to remittances. These flows of labor and capital can alter economic inequality and growth in an open economy where capital moves freely while labor movements are subject to an exogenous fixed cost. We consider the migration decision as an alternative investment to produce economic growth, and study its consequences. Migration can increase investments in education and increase human capital acquisition. These changes in human capital have consequences on inequality in labor-sending developing countries. The questions that we will address in our analysis are the following: Do migration and remittances increase or decrease inequality in migrants' home countries? Do the inequality patterns change over time? Does migration affect the factors that generate inequality? We consider productivity differences to explain the different effects that migration and remittances can have on inequality.

It is increasingly accepted that "education and migration decisions are likely to be jointly determined", Hanson (2010, p. 239). For this reason, our baseline endogenous migration model expands upon Docquier et al.'s (2010) model where households choose production and migration as a single decision unit. In their model, remittances are the channel to equalize and maximize household utility, and migration costs are exogenous at a constant value. Unlike Docquier et al., we endogenize the decision concerning the generation of human capital within households through investment in education. Human capital units are obtained by means of a continuous and concave technology that presents indivisibilities in education investment. One of the main differences between our work and Docquier et al. (2010) is that we obtain migrants' earnings and remittances proportional to their education level. In their pioneering study, Lucas and Stark (1985) point out that income and remittances increase with education. They study the motivations to remit for the case of Botswana. Recently, Grogger and Hanson (2011) stated that migrants choose their destinations depending on their possible earnings, which suggests that migrants' wages highly depend on their human capital level.

Recent studies have pointed out an inverse U-shaped relation between migration and inequality as already suggested by Stark, Taylor and Yitzaki (1986). Mckenzie and Rapoport (2007) observe an inverted U-shaped relation between wealth and migration history. They consider the migrant networks to be a channel for reducing migration costs and creating the possibility for the poorest families to migrate and become richer than they would without migration. Docquier et al. (2010) also explain the inverse U-shaped relation between migration history and income inequality. They argue that remittances might increase income inequality and reduce wealth inequality in economies with little history of migration, whereas remittances decrease income and wealth inequality in economies with a long history of migration. We seek to complement these studies by considering technological 
progress and the technological gap as alternative explanations for the relation between migration and inequality. Therefore, we highlight the importance of development as an engine to influence inequality and the effects of migration on inequality.

The relation between economic inequality and growth has been widely studied since the seminal study by Galor and Zeira (1993). They use different interest rates for borrowers and lenders and indivisibilities in education to prove that the aggregate output and investment is affected by the initial distribution of wealth in the short and the long run. We develop a model similar to Galor and Tsiddon's (1997) to study the evolution of inequality and migration through technological process. Galor and Tsiddon (1997) consider the level of aggregate human capital to be the necessary input for the evolution of technology. The level of technology determines the evolution of inequality and the process of development. They study the evolution of human capital from parents to children and how the aggregate distribution of human capital evolves over time. The interplay between parents and children's education (local effect) and the state of technology and education (global effect) generate convergence towards an unequal distribution of human capital in low technological levels, and towards an equal distribution in high technological levels. Since we are interested in the effects of migration on economic inequality, we also consider how both distributions of income and wealth evolve over time, and how these distributions are affected by the migration investment and the technological gap between migrants' source and destination countries.

We use a combination of migration decisions and technological levels to characterize and compute remittances. This amount of money enables households to increase their level of consumption and investment in migrants' home countries. The option of migration as a family investment implies a trade-off between education and migration decisions because of financial constraints. If the return on education is higher than the return on migration, the model predicts that some families decide to invest in education and send a share of the family abroad. Due to the higher earnings that they receive abroad, educated migrants will remit more than migrants without education as Bollard et al. (2011) point out. We also take into account the size of the household that stays in the birth country, since the amount of remittances highly depends on the relatives who do not migrate (Bollard et al. 2011). Because of financial constraints, the interaction between migration and education returns in the home and destination countries determines the education level. Once remittances alleviate the liquidity constraints of the poorest and most uneducated households, they prefer to invest in education because of its higher returns. Moreover, the higher returns in the destination country increase the amount that households can invest in education, and a higher technological level in the home country is related to a lower minimum level of education that makes it profitable to become educated. The possibility of migration can increase the minimum amount of wealth to make it profitable to be educated.

As the development process evolves, we observe two different regimes of migration rates, income and wealth inequality. At early stages of migration, migration rates increase and the differences in wealth and income between poor and rich families expand. At more advanced stages of technology, migration rates decrease if migration costs are fixed. If migration costs are reduced, migration increases as long as it is profitable. If a technological 
barrier that generates convergence towards a single wealth distribution is overcome, the differences in income and wealth between rich and poor households are reduced because all the individuals become educated and converge into an equal society. We consider the possibility that migration accelerates this evolution. Remittances increase wealth inequality but also decrease the threshold technology that reduces inequality in the economy. As in Galor and Tsiddon (1997), these results are in line with Kuznets' hypothesis, which supports the fact that developing countries experience an increase in economic inequality, whereas more developed countries experience a reduction in economic inequality over time.

\section{Stylized facts}

Migrant selection refers to the skills composition of migrants. Previous literature distinguishes between two types of workers -high- and low-skilled-in terms of their educational level. Previous literature states that there is positive (negative) selection of migrants if the ratio of high- to low-skilled migrants is higher (lower) than the same ratio for non-migrants. Here, we also consider the medium-skilled migrants to understand the composition and the wealth effects over selection better. In their characterization of migrant selection, Grogger and Hanson (2011) do not consider the medium-educated, instead they consider individuals with more or less than secondary education to be a proxy for high- and low-skilled individuals. However, Caponi (2010) studies the shape of selection of Mexican migrants to the US on four educational levels: no education, primary, secondary, and tertiary education. ${ }^{1}$ Similar to Caponi, we can look at different countries using the bilateral data on migration from Docquier et al. (2009). Therefore, we refer to migrant selection as the shape of selection.

Docquier et al.'s (2009) dataset provides information on migration to 30 OECD countries and South Africa disaggregated by countries of origin and three educational levels for the years 1990 and 2000. This dataset considers migrants above 25 years old; for this reason, we can use it as a proxy for migrants who have finished their education. The dataset distinguishes three general education groups: less than secondary education or low-skilled migrants; migrants with secondary education or medium-skilled migrants; and, more than secondary education or high-skilled migrants. We obtain three migration selection patterns with the exception of a few countries. ${ }^{2}$ Let us denote each selection pattern: J-shape if migration is very low for individuals with secondary or less education compared to the highly skilled ones; I-shape if migration increases with education; and U-shape if individuals with secondary education migrate less than the remainder. Figure 1 shows an example of each possible shape.

\footnotetext{
${ }^{1}$ Caponi (2010) explains the U-shaped relation between migration and education by the loss of human capital in migration and the altruism towards future generations.

${ }^{2}$ Some countries have a higher migration rate among individuals with secondary education than among other groups. These countries are Albania, Ecuador and Portugal for 1990 and 2000, Finland and Luxemburg for 1990, and El Salvador, Suriname and Venezuela for 2000 out of the 195 different countries considered.
} 
Figure 1 Migrant Selection Shapes.
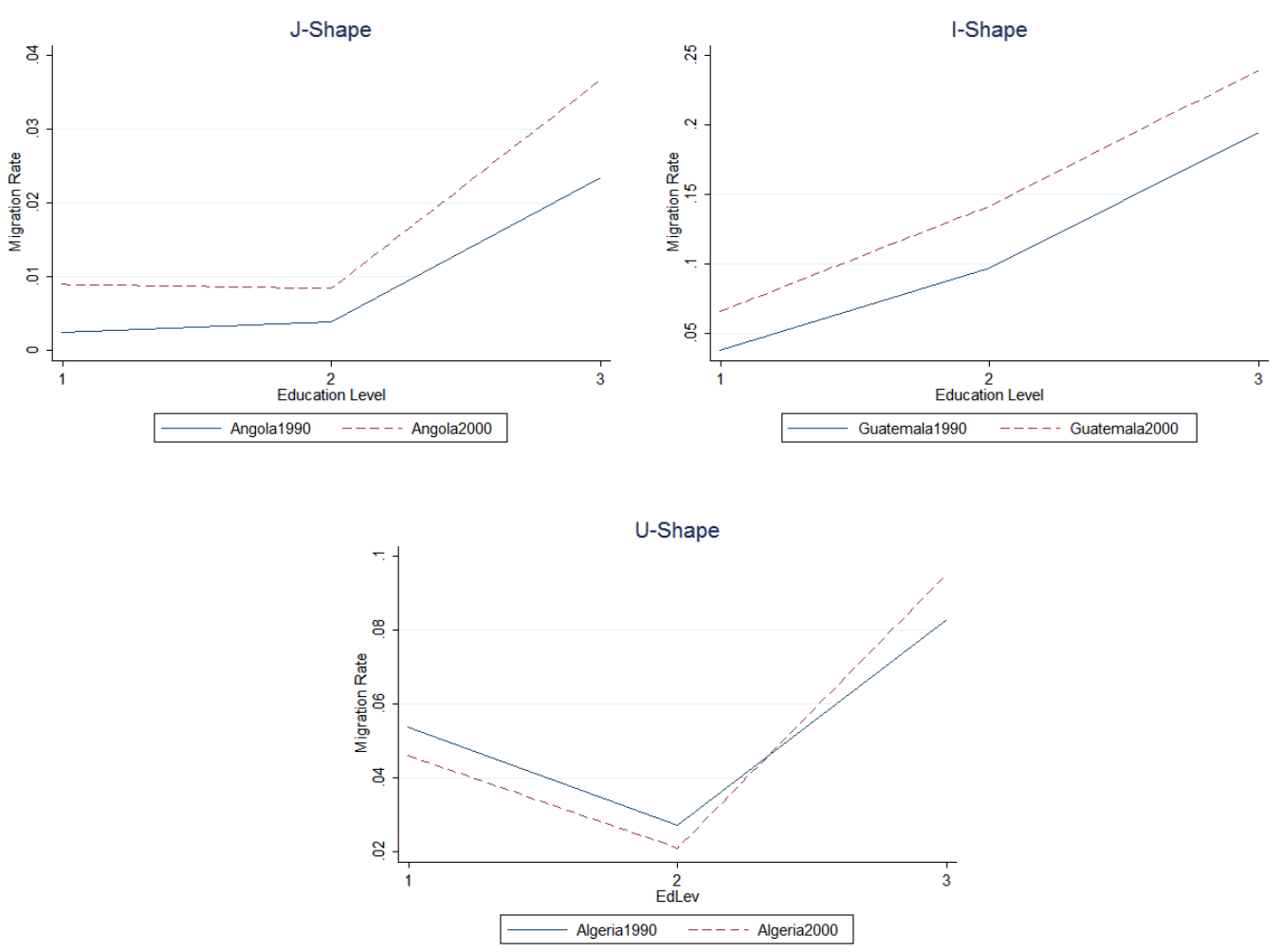

In order to classify countries in each group we proceed to define the groups. In the Jshaped group there are countries with low rates of migration for the low and medium skilled in comparison to the rates of migration for the highly skilled. Thus, we include in the Jshaped group countries in which the difference between migration rates of low and medium skilled is lower than $10 \%$ of the difference between the highest (high skilled) and lowest (medium or low skilled) rates of migration. In this group there are countries such as Chile, the UK, and most of the sub-Saharan and Asian countries. In the I-shaped group there are countries where there is a strictly increasing relation between the migration rate and the education level. Hence, we include in the I-shaped group countries in which the migration rates increase with education and the difference between the low- and the medium-skilled migration rate is higher than $10 \%$ of the difference between the low- and high-skilled rates of migration. In this group there are countries such as Belgium, Thailand, and most Latin American, North African and Middle East countries. Finally, in the U-shaped group there are countries with a low migration rate for the medium skilled compared to the low and high skilled, i.e., the medium skilled have the lowest migration rate, and the difference of migration rates between low and medium skilled is higher than $10 \%$ of the difference between medium and high skilled. Some examples are Mexico, Algeria, Turkey, and most 
of the OECD, former USSR, and former Yugoslavian countries. ${ }^{3}$

Figure 2 Migrant selection by GDP groups.

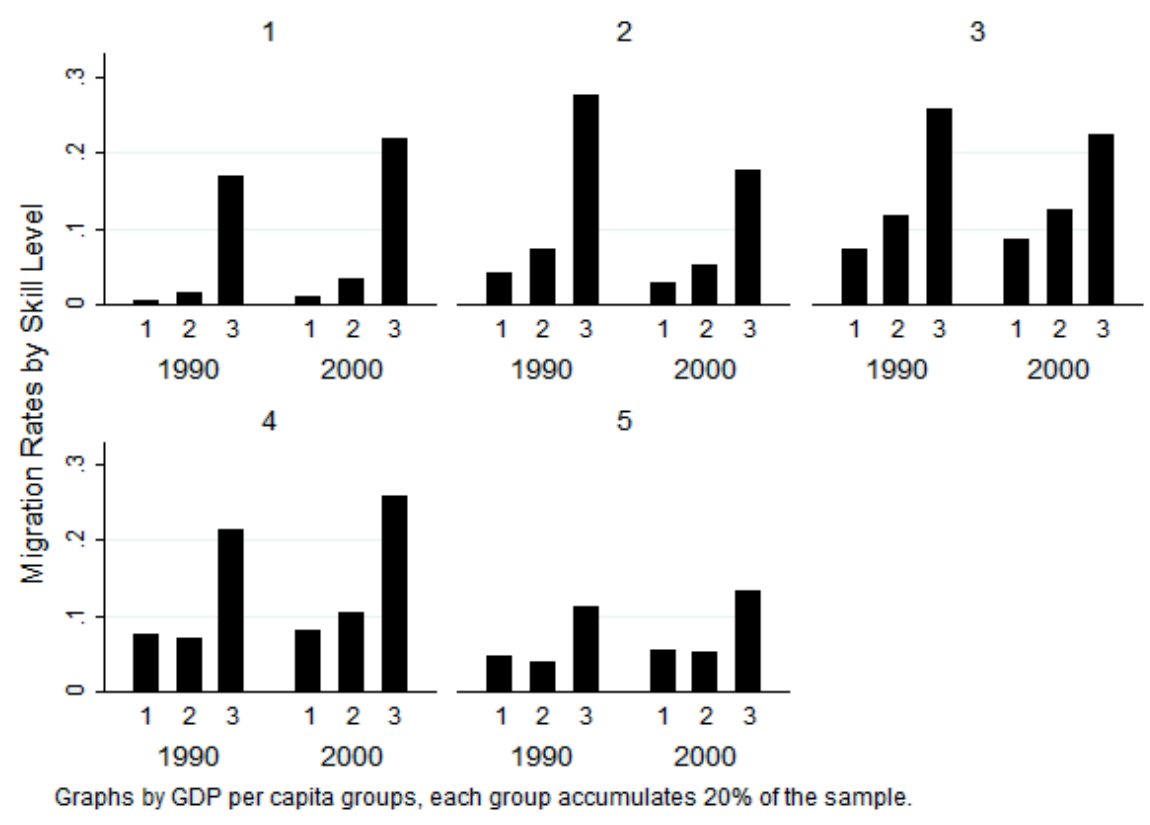

In Figure 2 we can observe the average migration rates by educational group, year, and level of GDP per capita. Each of the 5 subgraphs accumulates $20 \%$ of the countries ordered by GDP per capita, i.e., the first graph includes the $20 \%$ of countries with the lowest GDP per capita and the fifth graph includes the countries with the highest GDP per capita. Furthermore, bars 1, 2 and 3 refer to low-, medium-, and high-skilled individuals for the years 1990 and 2000. This graph captures the fact that highly skilled individuals profit more from migration because they show the highest migration rates. For low GDP per capita levels, migration is much higher for the highly skilled than for the low skilled. Sub-graphs 1 to 3 show that as GDP per capita increases there is a higher increase in migration rates of low and medium skilled, hence the figures evolve from a J-type to an I-type of shape. A possible explanation of this change is lower binding constraints to migrate. In the last sub-graphs 4 and 5 there is a reduction in migration rates, especially for the medium skilled. The final subgraph shows that very rich economies have lower migration rates as suggested in the previous subsection. The model presented in the next section fails to capture selection in the most advanced economies, which tend to show a U-shaped relation although the model predicts that only highly educated individuals profit from migration due to low technological differences. Notwithstanding, this failure may reflect how in advanced economies, wealth constraints do not matter as much as in nondeveloped countries for migrant selection or how migration costs are much lower among

\footnotetext{
${ }^{3}$ See Appendix for a complete classification of countries.
} 
developed countries.

Although there may be other explanations, wealth constraints (due to low levels of development and high migration costs) seem to play an important role in explaining the migration shape. There are other studies such as Fernández-Huertas (2013) that also emphasize the effects of the wealth constraints on determining migrant selection. ${ }^{4}$ In our model, there are two main forces driving migration; wage differences and migration costs. However, we should also consider the wealth distribution and educational costs as two key elements of the model that determine the size of each education subgroup and the size of migration in each subgroup.

The model described in the next section is also consistent with previous migration literature. Mayda (2010) and Grogger and Hanson (2011), among others, use different datasets on bilateral migration flows to OECD countries to explain the determinants of migration size. The main forces driving migration are differences in income and migration costs. At the same time, Beine et al. (2011) use diasporas as a channel to explain the network effects of reducing migration costs and the flow of migration. Nevertheless, we did not endogenize migration costs through previous migration to simplify the exercise, the introduction of decreasing costs would not change the main conclusions of the paper. Similar to the previous works above we use differences in productivity levels that explain income differences and migration costs.

The study of the evolution of inequality started with the seminal work by Kuznets (1955). He pointed out that inequality increases in the first stages of development and decreases in the more advanced stages. Hence, inequality has an inverted-U shape in relation to economic development. Different authors have supported and criticized Kuznets' hypothesis. ${ }^{5}$ Barro (2000) concludes that it seems to appear as an empirical regularity but the level of economic development does not explain the variations in inequality across countries or over time. Other authors have observed that inequality is increasing among developed countries because of the increasing demand for skills, but there is still a higher concentration of developed countries around low levels of inequality than the levels of inequality of not so developed countries.

Although it is not directly considered in this work, the network effects of migration on inequality also seem to have an inverted-U shape. McKenzie and Rapoport (2007) describe this for two regions in rural Mexico. They find that migration increases inequality in the region with lower history of migration but decreases inequality in the region with a longer history of migration. However, they cannot observe the evolution of inequality and development in the same regions over time, they only observe each region twice in time. Previous authors have suggested this relation before but it could not be tested empirically due to a lack of data. As we have observed in the previous sections, selection is highly persistent. Migrant networks tend to increase the negative selection of migrants because

\footnotetext{
${ }^{4}$ Fernández-Huertas (2013) concludes that higher skill prices in urban Mexico than in the US explain the negative migrant selection in urban Mexico. However, skill prices are not enough to generate negative selection in rural Mexico. He also concludes that the low prevalence of network effects lower the negative selection, and that wealth constraints must be added to explain the positive selection.

${ }^{5}$ Even the causal relationship between economic growth and inequality is criticized by Quah (2003).
} 
previous migration may reduce the cost. Although the model is not directly reproducing migrant networks, we discuss a reduction in migration costs which generates this type of relation between migration and inequality. In line with our study, in order to observe such types of movement in the data we need countries with a high enough level of development and sufficiently low migration costs, which is what we observe in the case of Mexico. ${ }^{6}$

In order to study the effects of migration on inequality, on the one hand we construct a theoretical model that satisfies the main stylized facts that determine migration, on the other hand we have introduced the migration decision to a framework that reproduces the evolution of inequality in relation to economic growth in line with some authors in the field.

\section{The model}

\subsection{Production}

Consider a small open economy in discrete time where aggregate production of a single final good is given by a constant returns to scale neoclassical production function. In every period $t$, production takes place using aggregate physical capital $K_{t}$ and efficiency units of labor. The efficiency units of labor are the product of aggregate human capital $H_{t}$, and labor productivity $A_{t}$ related to the level of technology. We assume that productivity evolves according to an exogenous sequence $\left\{A_{t}\right\}_{t=0}^{\infty}$. Output $Y_{t}$ produced at time $t$ is

$$
Y_{t}=F\left(K_{t}, A_{t} H_{t}\right)=A_{t} H_{t} f\left(k_{t}\right),
$$

where $k_{t}=K_{t} /\left(A_{t} H_{t}\right)$ is the physical capital to efficiency units of labor ratio. The production function $f\left(k_{t}\right)$ is strictly increasing, strictly concave and satisfies the Inada conditions,

$$
f(0)=0, \lim _{x \rightarrow 0} f^{\prime}(x)=+\infty, \lim _{x \rightarrow+\infty} f^{\prime}(x)=0 .
$$

We normalize the price of the final good to 1, i.e., we take the output good as the numéraire. In a competitive equilibrium each factor price equals its marginal product,

$$
r_{t}=F_{K}\left(K_{t}, A_{t} H_{t}\right)=f^{\prime}\left(k_{t}\right),
$$

and

$$
w_{t}=F_{H}\left(K_{t}, A_{t} H_{t}\right)=A_{t}\left(f\left(k_{t}\right)-f^{\prime}\left(k_{t}\right) k_{t}\right)=A_{t} w\left(k_{t}\right),
$$

where $r_{t}$ is the return on physical capital and $w_{t}$ is the return on human capital.

As a result of the assumption of a small open economy, physical capital flows into or out of the country so that the marginal product of physical capital is equal to the constant

\footnotetext{
${ }^{6} \mathrm{Ha}$ et al. (2009) obtained an equivalent result for internal migration in China using village panel data. Both studies control for the effects of per capita income and find that it is not significant but increases inequality (positive coefficient in the regression).
} 
world interest rate $\bar{r}$. The constancy of the world interest rate implies that the physical to efficiency units of labor ratio is fixed over time $K_{t} /\left(A_{t} H_{t}\right)=k_{t}=\bar{k}$. Hence,

$$
r_{t}=\bar{r}, \quad \text { and } \quad w_{t}=A_{t} \bar{w} .
$$

The acquisition of human capital depends on investment in education. Individuals can acquire an education level $e$ through wealth investment. We consider a continuous human capital technology as in Galor and Tsiddon (1997), Vidal (1998) and Ceroni (2001), among others. However, a minimum education investment is necessary to increase the human capital efficiency units. A share of the expenditure on goods is allocated to education. The human capital production function is given by

$$
h(e)= \begin{cases}\mu & \text { if } e \leq e_{0} \\ \mu+\left(e-e_{0}\right)^{\eta} & \text { if } e>e_{0}\end{cases}
$$

where $\mu \geq 0, \eta \in(0,1)$, and $e_{0} \geq 0$. The human capital technology satisfies $h(0)=\mu$, for all $e>e_{0} h^{\prime}(e)>0$ and $h^{\prime \prime}(e)<0, \lim _{e \rightarrow e_{0}^{+}} h^{\prime}(e)=\infty$ and $\lim _{e \rightarrow \infty} h^{\prime}(e)=0 .^{7}$ Hence, the level of human capital is an increasing function of wealth investment with diminishing returns.

\subsection{Economy without international labor mobility}

The economy is modeled as an overlapping generation of dynasties. There is a continuum of households of size $N$ composed of a continuum of individuals who live for two periods. Without loss of generality we assume that the size of the household is 1 . Households differ in the initial distribution of wealth although we assume that all the members in the household equally share their wealth and education level.

In the first period, households receive a wealth endowment $b_{t}^{i}$ from their parents. With this endowment, the household decides how much to invest in education $e_{t}^{i}$ and savings $s_{t}^{i}$. In the second period, individuals work, consume, and make transfers to their offspring. Each individual has a single child, and parents retire at the end of the second period. There is no population growth.

Utility is derived from consumption and bequests to their offspring in the second period of life. The second-period utility function is

$$
U_{t+1}=\log \left(c_{t+1}^{i}\right)+\gamma \log \left(b_{t+1}^{i}\right) .
$$

Therefore, the utility function exhibits "joy of giving" preferences since parents obtain utility from the transfers to their children rather than from the utility of their children. We impose that $\gamma \bar{r}<1$, which implies that bequests do not grow unboundedly.

\footnotetext{
${ }^{7}$ Among others, Galor and Tsiddon (1997) use this type of technology. They extend this technology to the case of there being diminishing complementarity between investment in wealth and parents' level of human capital.
} 
In period $t$, a household with inherited wealth $b_{t}^{i}$ maximizes utility given prices $\bar{r}, w_{t+1}$ subject to the following constraints:

$$
\begin{gathered}
s_{t}^{i} \geq 0 ; \\
e_{t}^{i}+s_{t}^{i}=b_{t}^{i} ; \\
c_{t+1}^{i}+b_{t+1}^{i}=w_{t+1} h\left(e_{t}^{i}\right)+(1+\bar{r}) s_{t}^{i} ;
\end{gathered}
$$

where constraint (1) states that households can invest in the international capital markets but they cannot borrow; constraint (2) says that households can invest their wealth endowment in education and/or savings; and constraint (3) means that households choose per capita consumption and bequests in the second period, which exhaust household income. At the same time, household income is the return on savings and salary, which depends on the education level. Moreover, because of the functional form for the utility function, consumption and bequests are positive, i.e., $c_{t}>0$ and $b_{t}>0$.

Given the assumption regarding the utility function and the human capital production function, there is a single equilibrium solution for each amount of inherited wealth to the maximization problem. The homothetic preferences assumption over consumption and bequests implies that households maximize income, and spend a share $1 /(1+\gamma)$ of income on consumption and a share $\gamma /(1+\gamma)$ on bequests.

Let $\underline{e}\left(A_{t}\right)$ be the minimum amount invested in education for which is worth becoming educated, so $\underline{e}\left(A_{t}\right)>e_{0}$. Therefore, $\underline{e}\left(A_{t}\right)$ is the minimum education investment for the wage income to be equal to the income without education, i.e.,

$$
A_{t} \bar{w} h\left(\underline{e}\left(A_{t}\right)\right)=(1+\bar{r}) \underline{e}\left(A_{t}\right)+A_{t} \bar{w} \mu .
$$

Let $\bar{e}\left(A_{t}\right)$ be the maximum amount invested in education, $\bar{e}\left(A_{t}\right) \geq \underline{e}\left(A_{t}\right)$. It is the education investment in order for the return on education to be equal to the return on savings,

$$
\bar{e}\left(A_{t}\right)=\left(h^{\prime}\right)^{-1}\left(\frac{1+\bar{r}}{A_{t} \bar{w}}\right)=e_{0}+\left(\frac{\eta A_{t} \bar{w}}{1+\bar{r}}\right)^{\frac{1}{1-\eta}} .
$$

We only consider sufficiently high technological levels in order to ensure the existence of $\underline{e}\left(A_{t}\right)$. Otherwise nobody chooses to become educated and the economy converges into a situation where nobody is educated. The human capital technology ensures the existence of $\bar{e}\left(A_{t}\right)$, since the marginal returns on education are decreasing from infinity to zero. We can observe from (4) that the minimum education level $\underline{e}\left(A_{t}\right)$ decreases as the level of technology $A_{t}$ increases. In contrast, from (5) we observe that the maximum education level $\bar{e}\left(A_{t}\right)$ increases as the level of technology $A_{t}$ increases.

When households maximize income, they choose the level of education and savings as a function of the inherited wealth.

a. If $b_{t}^{i} \leq \underline{e}\left(A_{t}\right)$, then $e_{t}^{i}=0$ and $s_{t}^{i}=b_{t}^{i}$.

If the wealth of the household is not high enough to make it profitable to become educated, they generate wealth without education. 
b. If $\underline{e}\left(A_{t}\right)<b_{t}^{i}<\bar{e}\left(A_{t}\right)$, then $e_{t}^{i}=b_{t}^{i}$ and $s_{t}^{i}=0$.

If the wealth of the household is high enough to make it profitable to become educated, households choose the maximum possible level of education that they can pay for. As they cannot afford the optimal level of education, they do not save and invest all their wealth in education.

c. If $b_{t}^{i} \geq \bar{e}\left(A_{t}\right)$, then $e_{t}^{i}=\bar{e}\left(A_{t}\right)$ and $s_{t}^{i}=b_{t}^{i}-\bar{e}\left(A_{t}\right)$.

If the household wealth is higher than the optimal educational investment, households spend the optimal amount on education, and the rest of their wealth is saved and invested in international capital markets.

Therefore, given the technological level $A_{t}$ and the level of inherited wealth $b_{t}^{i}$, we can obtain the optimal savings $s_{t}^{i}=s\left(b_{t}^{i}, A_{t}\right)$ and education $e_{t}^{i}=e\left(b_{t}^{i}, A_{t}\right)$ decisions, and the optimal human capital efficiency units $h_{t}^{i}=h\left(e_{t}^{i}, A_{t}\right)=h\left(e\left(b_{t}^{i}, A_{t}\right)\right)$ that households supply.

\subsubsection{The evolution of wealth within a dynasty}

In the previous section we characterized the amount devoted to bequests for every dynasty as a function of the inherited wealth. At the same time, this amount is the inherited wealth of the next generation. Hence, the evolution of bequests characterizes the household wealth evolution. Figure 3 shows the evolution of bequests for two different technological levels: high and low, where subscript $h$ denotes high and subscript $l$ denotes low. As noticed before, the interval between the minimum and maximum values of education expands with the technological level $A_{t}$. Therefore, we can characterize the evolution of bequests within a dynasty as a function of their initial wealth.

The wealth dynamics of dynasties are given by

$$
\begin{aligned}
& b_{t+1}^{i}=\psi\left(b_{t}^{i}, A_{t}\right) \\
& = \begin{cases}\frac{\gamma}{1+\gamma}\left(A_{t} \bar{w} \mu+(1+\bar{r}) b_{t}^{i}\right) & \text { if } b_{t}^{i} \leq \underline{e}\left(A_{t}\right) \\
\frac{\gamma}{1+\gamma} A_{t} \bar{w}\left(\mu+\left(b_{t}^{i}-e_{0}\right)^{\eta}\right) & \text { if } \underline{e}\left(A_{t}\right)<b_{t}^{i} \text { and } b_{t}^{i}<\bar{e}\left(A_{t}\right) \\
\frac{\gamma}{1+\gamma}\left(A_{t} \bar{w}\left(\mu+\left(\frac{\eta A_{t} \bar{w}}{1+\bar{r}}\right)^{\frac{\eta}{1-\eta}}\right)+(1+\bar{r})\left(b_{t}^{i}-\bar{e}\left(A_{t}\right)\right)\right) & \text { if } b_{t}^{i} \geq \bar{e}\left(A_{t}\right) .\end{cases}
\end{aligned}
$$

We can consider different technological levels. For the moment we only consider the case where the technological level is fixed over time at level $A$. Let $\widehat{A}$ be the technological level for which the long-run distribution converges towards a single steady state if the technological level is higher than $\widehat{A}$, and the long-run distribution converges to two steady states if the technological level is lower than $\widehat{A}$. The following proposition characterizes the evolution of dynasties when the technological level is fixed over time. ${ }^{8}$

\footnotetext{
${ }^{8}$ Proposition equivalent to Proposition 2.2 in Galor and Tsiddon (1997).
} 
Figure 3 Evolution of bequests across dynasties for $A_{h}$ and $A_{l}$ with $A_{h}>A_{l}$.

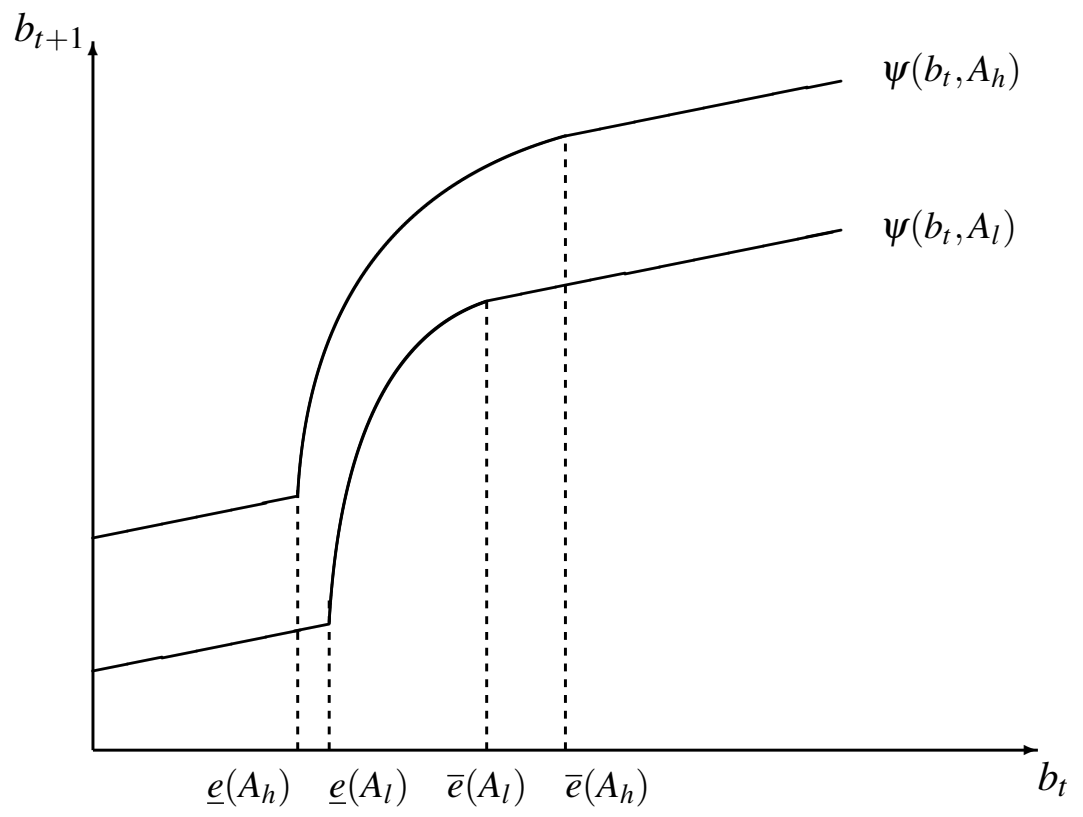

Proposition 1. Consider the dynamical system $b_{t+1}^{i}=\psi\left(b_{t}^{i}, A\right)$.

If the dynamical system displays a single steady-state equilibrium, then

$$
\lim _{t \rightarrow \infty} b_{t}^{i}=b^{s}(A)
$$

If the dynamical system displays three steady state equilibria, then

$$
\lim _{t \rightarrow \infty} b_{t}^{i}= \begin{cases}b^{a}(A) & \text { if } b_{0}^{i} \in\left[0, b^{b}(A)\right) \\ b^{c}(A) & \text { if } b_{0}^{i} \in\left(b^{b}(A), \infty\right) .\end{cases}
$$

Proof. As can be seen in Figure 4, the dynamical system $b_{t+1}^{i}=\psi\left(b_{t}^{i}, A\right)$ converges to a single steady state or to three steady states. The technological level determines the number of steady states. If the level of technology $A \equiv A_{h}$ is higher than the threshold technology $\widehat{A}$ the system converges to a single steady state $b^{s}\left(A_{h}\right)$. Whereas, if the technological level $A \equiv A_{l}$ is lower or equal than $\widehat{A}$ the system has three steady states $b^{a}\left(A_{l}\right), b^{b}\left(A_{l}\right)$, and $b^{c}\left(A_{l}\right)$, where $b^{a}\left(A_{l}\right)$ and $b^{c}\left(A_{l}\right)$ are stable and $b^{b}\left(A_{l}\right)$ is unstable.

Given a technological level, the initial distribution of wealth characterizes the long-run distribution of wealth. If the dynamics of bequests are characterized by three steady states, the long-run distribution is polarized, whereas if the dynamics of bequests are characterized by a single steady state, the long-run distribution converges to a single point and the 
Figure 4 Evolution of bequests across dynasties for $A_{h}>\widehat{A}$ and $A_{l}<\widehat{A}$.

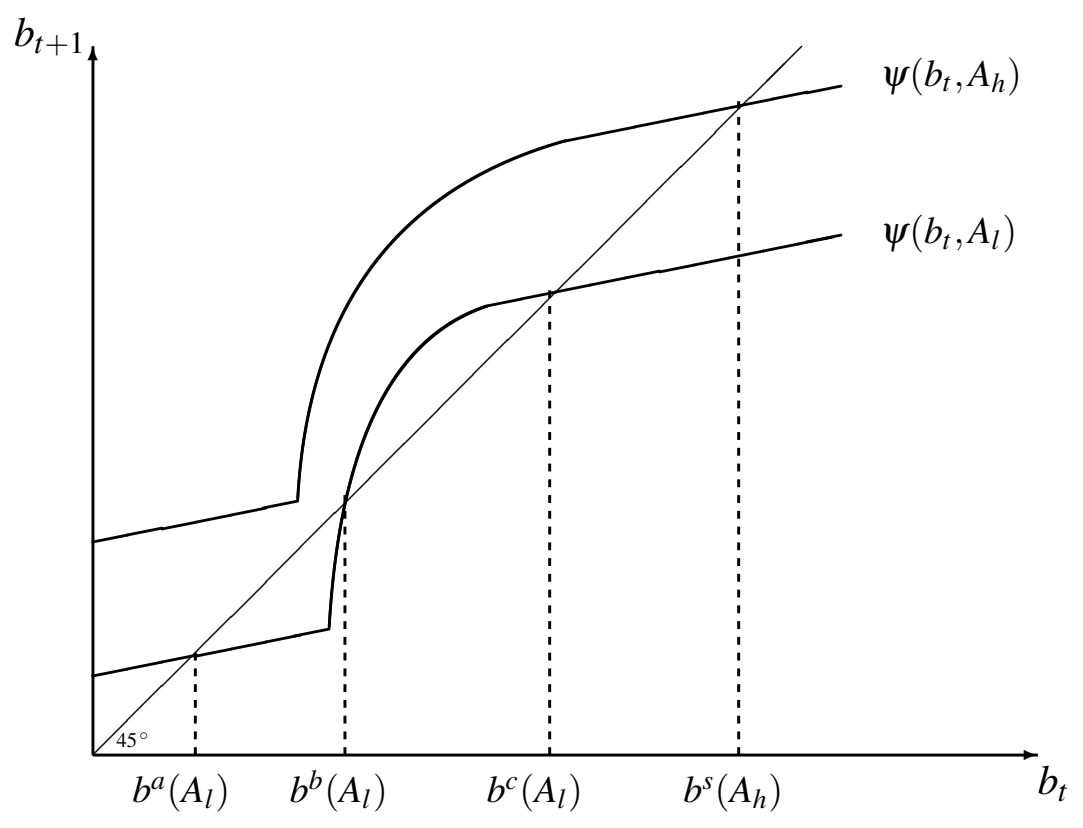

economy is equally distributed. Thus, there are two different wealth distribution patterns in the long run that depend on the technological level. Hence, if the technological process surpasses the technological level $\widehat{A}$, households converge towards an equally distributed economy, whereas if the technological process does not surpass the technological level $\widehat{A}$, the economy converges towards a polarized and unequally distributed economy.

\subsubsection{The evolution of the wealth distribution and technological progress}

In the previous section we observed that the technological level determines wages, income and next generation wealth. Hence, the sequence of factor productivities $\left\{A_{t}\right\}_{t=0}^{\infty}$ characterizes the wealth evolution of dynasties and the aggregate wealth distribution over time. In this section we characterize the aggregate wealth distribution to obtain the evolution of wealth inequality in the economy.

Suppose that the density function $g_{0}\left(b_{0}^{i}\right)$ characterizes the wealth distribution of the parent generation in time 0 . Because households cannot hold debt to their children in any period, i.e., $b_{t}>0$ for all $t$, the positive real numbers are the support of the density function in all periods. We assume that the size of the continuum of households is constant and equal to $N$, therefore,

$$
\int_{0}^{\infty} g_{t}\left(b_{t}^{i}\right) d b_{t}^{i}=N, \quad t=0,1,2, \ldots
$$

For a stationary technological level $A$, the number of steady state equilibria of the wealth dynamics characterizes the aggregate human capital distribution in the long run. If there are multiple steady state equilibria, the number $L^{u}$ of low-skilled households in the long 
run is

$$
L^{u}=\int_{0}^{b^{b}(A)} g_{t}\left(b_{0}^{i}\right) d b_{t}^{i}
$$

and the number $L^{s}$ of high-skilled households is

$$
L^{s}=\int_{b^{b}(A)}^{\infty} g_{t}\left(b_{0}^{i}\right) d b_{t}^{i}
$$

The following proposition summarizes the long-run distribution for a level of technology A. ${ }^{9}$

Proposition 2. Consider a stationary technological level A.

If the dynamical system $b_{t+1}^{i}=\psi\left(b_{t}^{i}, A\right)$ displays a single steady state equilibrium $b^{s}(A)$, then

$$
\lim _{t \rightarrow \infty} g_{t}\left(b_{t}^{i}\right)=b^{s}(A),
$$

i.e., the long-run distribution of wealth is a point $b^{S}(A)$ of mass $N$.

If the dynamical system $b_{t+1}^{i}=\psi\left(b_{t}^{i}, A\right)$ displays three steady-state equilibria $\left(b^{a}(A)\right.$ and $b^{c}(A)$ are locally stable, and $b^{b}(A)$ is locally unstable), then

$$
\lim _{t \rightarrow \infty} g_{t}\left(b_{t}^{i}\right)= \begin{cases}b^{a}(A) & \text { if } b_{0}^{i}<b^{a}(A) \\ b^{c}(A) & \text { if } b_{0}^{i}>b^{b}(A),\end{cases}
$$

i.e., the long-run distribution of wealth is a two point distribution with a mass of $L^{u}$ in $b^{a}(A)$ and a mass of $L^{s}$ in $b^{c}(A)$.

Proof. It follows from Proposition 1.

For a given stationary level of technology, the initial distribution of wealth determines the long-run distribution of wealth. If the wealth dynamics display two locally stable steady states, the density function converges to a two mass points distribution. Hence, the economy converges towards a polarized economy with a mass $L^{u}$ of poor households and a mass $L^{s}$ of rich households, which may induce inequality in the distribution of income. However, if the wealth dynamics display a single steady state, the density function converges to a single mass point distribution. In this case, the economy converges towards a uniform and equally distributed economy composed of high-skilled households, regardless of the initial distribution.

For every dynasty, given the initial level of wealth $b_{0}^{i}$ and the technology level $A_{t}$, the function $\psi$ characterizes the bequests that households leave to their children. Thus, given the sequence of technological levels $\left\{A_{t}\right\}_{t=0}^{\infty}$, the aggregate distribution in the next period follows from the distribution in the initial period, i.e., $g_{1}\left(b_{1}^{i}\right)=g_{0}\left(\psi^{-1}\left(b_{1}^{i}, A_{0}\right)\right)$. In fact, we can generalize this relation for all the periods,

$$
g_{t+1}\left(b_{t+1}^{i}\right)=g_{t}\left(\psi^{-1}\left(b_{t+1}^{i}, A_{t}\right)\right) .
$$

\footnotetext{
${ }^{9}$ Proposition equivalent to Proposition 3.1 in Galor and Tsiddon (1997).
} 
If technology is nondecreasing, i.e., $A_{t+1} \geq A_{t}$ for all $t$, for the same inherited wealth, households invest in education at least the same amount of wealth in the next period, because the returns on education are higher. Moreover, some of the households that do not invest in education, will invest in education in the next period because the minimum level of investment $\underline{e}\left(A_{t}\right)$ diminishes. Hence, the group of individuals $L^{s}$ that tends to the higherwealth steady state can increase because the wealth $b^{b}\left(A_{t}\right)$ that determines the size of the group in the long run diminishes as well, and, consequently, group $L^{u}$ decreases. Therefore, the higher investment in education by the high-skilled group leads to increases in output in conjunction with an increase in the polarization of the distribution of wealth, human capital, and income. Figure 5 shows the long-run distribution of wealth for an economy that has experienced a TFP increase (from $A_{l}$ to $A_{h}$ ). Moreover, the size of both unskilled and skilled workers is the same for the low TFP level. Thus, an increase in the TFP level increases the distance between the two mass points (increase in polarization) and the size of the high-skilled group (changes in inequality). In the long run, a change in TFP only changes the distance between the two mass points and not the size of each group. Therefore, inequality evolves as polarization does, inequality and polarization increase if TFP increases and is lower than the threshold level $\widehat{A}$, and inequality and polarization are reduced if TFP increases and surpasses $\widehat{A}$.

Figure 5 Effects of an increase of the TFP in the long-run wealth distribution.

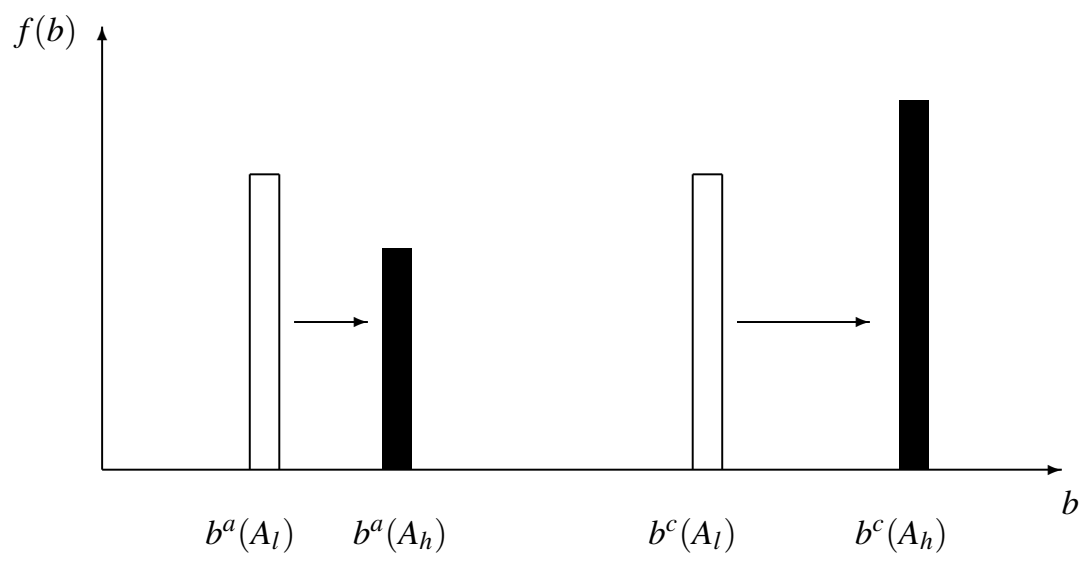

If we assume that there is a time period $\widehat{t}$ in which the technological level exceeds the threshold $\widehat{A}$, then, the dynamical system $b_{\widehat{t}+1}^{i}=\psi\left(b_{t}^{i}, A_{\widehat{t}}\right)$ displays a single steady state. From this period onwards, the economy converges towards a decrease in polarization in the distribution of wealth, human capital, and income.

Hence, in time periods in which the dynamical system $b_{t+1}^{i}=\psi\left(b_{t}^{i}, A_{t}\right)$ displays multiple steady-state equilibria, the distribution of wealth gravitates towards increased polarization, whereas in periods in which the dynamical system displays a single globally stable steady-state equilibrium the distribution of wealth gravitates towards diminished polarization. Therefore, in the long run, inequality increases or decreases if the technological threshold $\widehat{A}$ has or has not been overcome. 


\subsection{Economy with international labor mobility}

In the previous section we assumed that labor was immobile. In the following sections we let households have access to migration. Households can achieve a higher wage in a destination country. Migration is an alternative investment that enables households to increase their income. This extra source of income can mitigate the borrowing constraints to invest in education for the next generation. We assume that the destination country has an equivalent production function except for the technological level. We also assume that the level of technology in the destination country is the technology frontier $\bar{A}$ and $\bar{A} \geq \widehat{A}$, then inequality decreases in the destination country. The home country's productivity evolves according to the sequence $\left\{A_{t}\right\}_{t=0}^{\infty}$. We treat the households' home country as a developing country, whereas the destination country is treated as a developed one. This assumption is in line with Kuznets' hypothesis: more advanced economies tend to be more equally distributed than developing ones

For simplicity's sake, we assume that the wage in the destination country does not change with migration. The arrival of new workers does not affect the labor share in the receiving economy. We make this assumption because we are interested in the effects in migrants' home countries. Furthermore, many studies reveal small effects or even no effects of migration on wages in the host country, although part of the literature still does not agree. ${ }^{10}$

In the previous section, households received a wealth endowment $b$ from their parents in the first period. With this endowment, households decided education $e$ and savings $s$. Now, they also decide the share $m$ of the household that migrates at the end of the first period. In the second period, individuals consume and bequeath to their offspring. The share of the household can be related to the number of people who move, and the time spent in the migration country. If the household migrates, it has to pay a fixed cost $F$ proportionate to the share of the household that migrates. ${ }^{11}$

Migrants also decide the quantity to remit that maximizes the household utility. Remittances $R$ correspond to the direct transfers that migrants send to their family. All members of the household pay for the costs of migration, and migrants remit to compensate for these costs.

As in the economy without migration, utility is derived from consumption and bequests to offspring in the second period of life. Individuals decide the share $m_{t}$ of the household that migrates, and utility depends on whether there is a share of the household that migrates or not. The second-period utility function is

$$
U_{t+1}=m_{t} \log \left(c_{t+1}^{i, f}\right)+\left(1-m_{t}\right) \log \left(c_{t+1}^{i, h}\right)+\gamma\left(m_{t} \log \left(b_{t+1}^{i, f}\right)+\left(1-m_{t}\right) \log \left(b_{t+1}^{i, h}\right)\right),
$$

where superscript $f$ denotes foreign consumption and bequests, those of migrants, and superscript $h$ denotes home consumption and bequests, those of non-migrants. This utility

\footnotetext{
${ }^{10}$ Some examples of no effects of migration on wages are: Friedberg and Hunt (1995), Ottaviano and Peri (2012). An example of effects of migration on low-skilled wages is Borjas (2003).

${ }^{11}$ This type of cost is used by Docquier et al. (2010) in a dynamic framework and McKenzie and Rapoport (2007) in a static one.
} 
function puts weights on the migrant and non-migrant part of the household, proportional to the size of the household that migrates. The weights equate the migrant and the nonmigrant per capita consumption and bequests in equilibrium. ${ }^{12}$

In period $t$, a household with inherited wealth $b_{t}^{i}$ maximizes utility given prices $\bar{r}, \bar{w}$ and technological levels $A_{t}$ and $\bar{A}$ subject to the following constraints:

$$
\begin{gathered}
s_{t}^{i} \geq 0 ; \\
e_{t}^{i}+s_{t}^{i}+m_{t}^{i} F=b_{t}^{i} ; \\
m_{t}^{i}\left(c_{t+1}^{i, f}+b_{t+1}^{i, f}\right)+R_{t+1}^{i}=m_{t}^{i}\left(\bar{A} \bar{w} h\left(e_{t}^{i}\right)+(1+\bar{r}) s_{t}^{i}\right), \quad \text { if } m_{t}^{i}>0 ; \\
\left(1-m_{t}^{i}\right)\left(c_{t+1}^{i, h}+b_{t+1}^{i, h}\right)=\left(1-m_{t}^{i}\right)\left(A_{t+1} \bar{w} h\left(e_{t}^{i}\right)+(1+\bar{r}) s_{t}^{i}\right)+R_{t+1}^{i}, \quad \text { if } m_{t}^{i}<1 ; \\
m_{t}^{i} \in[0,1] .
\end{gathered}
$$

Constraint (6) says that households can invest in international capital markets but they cannot borrow; (7) states that households can invest their wealth endowment in education, savings, and migration. Migration costs are proportional to the share of the household that migrates; (8) means that if there is a share of the household that migrates, the migrant share decides per capita consumption, bequests and remittances in the second period that exhaust the income in the destination country; constraint (9) means that, if the household has not fully migrated, the non-migrant share decides per capita consumption and bequests in the second period that exhaust the income in the birth country and the received remittances from the migrant share; and constraint (10) states that the migration share should be feasible. ${ }^{13}$

The assumption that households maximize utility as a unit implies that individuals within a household share costs and benefits. Let $c_{t+1}^{i}$ be a share $1 /(1+\gamma)$ of household income, i.e.,

$$
c_{t+1}^{i}=\frac{1}{1+\gamma}\left(\left(\bar{A} m_{t}+A_{t+1}\left(1-m_{t}\right)\right) \bar{w} h(e)+\left(1+r_{t}\right) s_{t}\right),
$$

and let $b_{t+1}^{i}$ be the remaining income, i.e.,

$$
b_{t+1}^{i}=\frac{\gamma}{1+\gamma}\left(\left(\bar{A} m_{t}+A_{t+1}\left(1-m_{t}\right)\right) \bar{w} h(e)+\left(1+r_{t}\right) s_{t}\right) .
$$

In the case of a share of the household migrating, i.e., for $m_{t}^{i} \in(0,1)$, we obtain

$$
c_{t+1}^{i, h}=c_{t+1}^{i, f} \equiv c_{t+1}^{i}, \quad \text { and } \quad b_{t+1}^{i, h}=b_{t+1}^{i, f} \equiv b_{t+1}^{i},
$$

\footnotetext{
${ }^{12}$ Docquier et al. (2010) use the same result but do not write the utility.

${ }^{13}$ One of the classical dichotomies in the migration literature is whether migrants maximize relative or absolute differences in income. The model uses absolute differences in wages and not relative differences to explain migration incentives. Grogger and Hanson (2011) highlight how absolute differences explain migration determinants better than relative differences as opposed to Borjas (1987).
} 
the levels of consumption and bequests are equal for the individuals who remain in the birth country and the ones who migrate. In the case of the entire household migrating $(m=1)$, then there is neither consumption nor bequests at home and

$$
c_{t+1}^{i, f} \equiv c_{t+1}^{i} \quad \text { and } \quad b_{t+1}^{i, f} \equiv b_{t+1}^{i} .
$$

If nobody in the household migrates $(m=0)$, then there is neither consumption nor bequests abroad and

$$
c_{t+1}^{i, h} \equiv c_{t+1}^{i} \quad \text { and } \quad b_{t+1}^{i, h} \equiv b_{t+1}^{i} .
$$

In the case of a share of the household migrating, remittances are the channel to equalize the level of consumption at home and abroad. This amount of money that migrants send back home allows households to increase and equate the level of consumption and utility. In equilibrium,

$$
R_{t+1}^{i}=m_{t}^{i}\left(1-m_{t}^{i}\right)\left(\bar{A}-A_{t}\right) \bar{w} h\left(e_{t}^{i}\right),
$$

remittances are a concave function of the migration share, and increase with the technological gap $\bar{A}-A_{t}$ between destination and source countries. ${ }^{14}$ Moreover, note that if $m=0$ or $m=1$, then $R_{t+1}^{i}=0$.

The education, savings and migration decisions are taken to maximize the second period household income. The previous problem can be compactly written as

$$
\max _{m_{t}^{i}, e_{t}^{i}, s_{t}^{i}} m_{t}^{i} \bar{A} \bar{w} h\left(e_{t}^{i}\right)+\left(1-m_{t}^{i}\right) A_{t} \bar{w} h\left(e_{t}^{i}\right)+(1+\bar{r}) s_{t}^{i}
$$

subject to

$$
\begin{gathered}
s_{t}^{i} \geq 0, \\
e_{t}^{i}+s_{t}^{i}+F m_{t}^{i}=b_{t}^{i}, \\
m_{t}^{i} \in[0,1] .
\end{gathered}
$$

As in the economy without migration, there are education levels that determine which individuals invest in education and what the maximum amount they invest is. Let $\underline{e}\left(\bar{A}-A_{t}\right)$ be the minimum amount invested in education that makes it profitable to become educated. And let $\bar{e}\left(\bar{A}-A_{t}\right)$ be the maximum amount invested in education. The maximum amount invested in education is at least as high as without migration when households consider migration to be an alternative investment. In fact, it is higher as long as migration is profitable for individuals. The possibility of higher returns in the destination country enlarges education investment, in other words, migration encourages higher education. In contrast, migration can be a disincentive for low levels of education. The minimum amount that makes it profitable to become educated is higher or equal to what it is without migration. This is because the possibility of migration makes households devote some resources to migration instead of starting to become educated.

\footnotetext{
${ }^{14}$ Expression (13) is equivalent to Docquier et al.'s (2010) expression with a quadratic production function. The expression is derived combining 8,11 and 12 .
} 
In the case of poor households finding it optimal to invest in savings, this could be because it is only profitable to migrate to highly educated households, or because migration is not profitable to anyone. In the case of migration returns being higher than savings returns, the optimal migration $m_{t}^{i}$ of a household with inherited wealth $b_{t}^{i}$ can be obtained from the maximization problem above as the maximum of the function

$$
\Phi\left(m_{t}^{i} \mid b_{t}^{i}\right)=\left(A_{t}+m_{t}^{i}\left(\bar{A}-A_{t}\right)\right) h\left(b_{t}^{i}-F m_{t}^{i}\right),
$$

where $m_{t}^{i} \in\left[0, \min \left\{b_{t}^{i} / F, 1\right\}\right]$. The function $\Phi$ takes into account the income produced when there are no savings, and households can invest in education and/or migration. Its domain reflects the liquidity constraints that households face.

We can distinguish two parts in the function that characterizes investment in migration. Figure 6 presents the function $\Phi$ for different domains. If $b_{t}^{i} \leq e_{0}$, this function is linear in $m_{t}^{i}$ since the returns on education are constant and households can only invest in migration. Although in Figure 6 it is increasing, it could be increasing or decreasing depending on the technological gap, as we discuss later. If $b_{t}^{i}>e_{0}$, the function is linear for $m_{t}^{i}>\left(b_{t}^{i}-e_{0}\right) / F$, and it is strictly concave for $m_{t}^{i} \leq\left(b_{t}^{i}-e_{0}\right) / F$.

Therefore, the function $\Phi$ defines a function $\phi_{m}$ that gives the optimal migration investment for every amount of inherited wealth, i.e., $m_{t}^{i}=\phi_{m}\left(b_{t}^{i}\right) .{ }^{15}$ In the case of there being two maximums we assume that the function $\phi_{m}$ gives the smallest migration share.

Figure 6 The function $\Phi$.
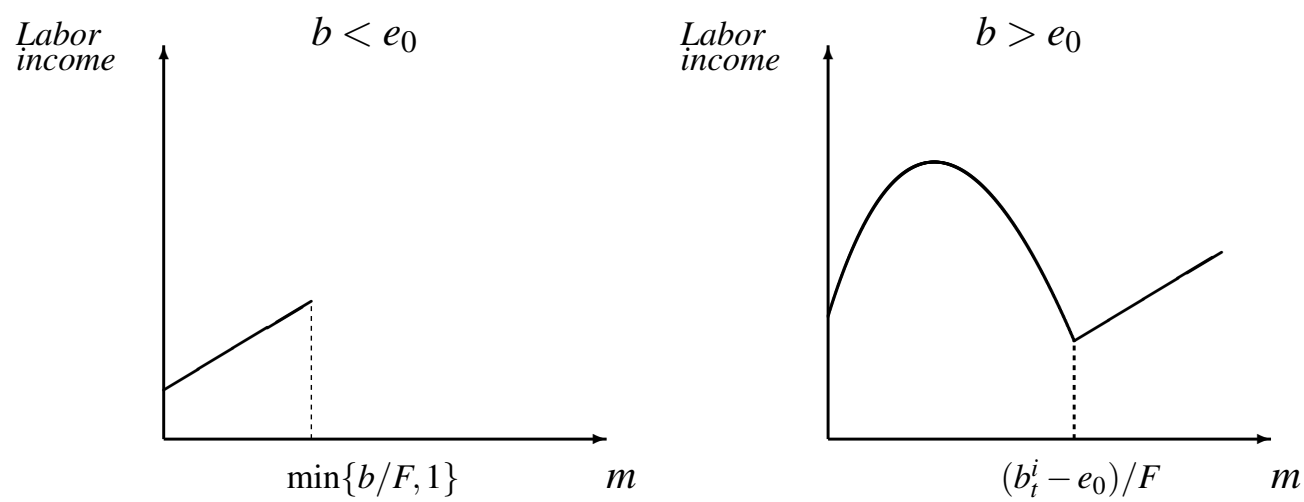

Note: the function $\Phi$ is not defined for values of $m$ higher than $\min \left\{b_{t}^{i} / F, 1\right\}$.

\footnotetext{
${ }^{15}$ The maximum exists because $\Phi$ is continuous and its domain $\left[0, \min \left\{b_{t}^{i} / F, 1\right\}\right]$ is a compact set. Note that if we apply the Implicit Function Theorem to the strictly concave part, the migration share increases as bequests do, i.e.,

$$
\frac{\partial \phi_{m}\left(b_{t}^{i}\right)}{\partial b_{t}^{i}}=\frac{\left(\bar{A}-A_{t}\right) h^{\prime}\left(b_{t}^{i}-F m_{t}^{i}\right)-F\left(m_{t}^{i} \bar{A}+\left(1-m_{t}^{i}\right) A_{t}\right) h^{\prime \prime}\left(b_{t}^{i}-F m_{t}^{i}\right)}{2\left(\bar{A}-A_{t}\right) h^{\prime}\left(b_{t}^{i}-F m_{t}^{i}\right)-F^{2}\left(m_{t}^{i} \bar{A}+\left(1-m_{t}^{i}\right) A_{t}\right) h^{\prime \prime}\left(b_{t}^{i}-F m_{t}^{i}\right)} \geq 0 .
$$
}


We can apply the same argument to the investment in education. Let $\phi_{e}$ be the function that gives the optimal education investment given the inherited wealth, i.e., $e_{t}^{i}=\phi_{e}\left(b_{t}^{i}\right) .{ }^{16}$

We can distinguish different optimal decisions that depend on the technological gap to migration costs ratio. We can consider three different regimes: High-, Low- and Nomigration regime. The returns on migration, education and savings characterize these regimes.

The High-migration regime occurs when the difference in technological levels is large enough and makes it worthwhile for all households to migrate. Migration costs are lower than the return on migration even for uneducated households,

$$
\left(\bar{A}-A_{t}\right) \bar{w} \mu>(1+\bar{r}) F .
$$

The Low-migration regime occurs when the difference in technological levels is not large enough, and it is only worthwhile for highly educated households to migrate. Migration costs are higher or equal than the return on migration for uneducated households, and the return on migration is higher than the migration costs and savings for highly educated households,

$$
\left(\bar{A}-A_{t}\right) \bar{w} \mu \leq(1+\bar{r}) F
$$

and

$$
\bar{A} \bar{w} h(\bar{e}(\bar{A}))-A_{t} \bar{w} h\left(\bar{e}\left(A_{t}\right)\right)>(1+\bar{r})\left(F+\bar{e}(\bar{A})-\bar{e}\left(A_{t}\right)\right) .
$$

Finally, the No-migration regime is the difference in technology levels which makes it not worthwhile for any household to migrate. The return on migration is lower or equal than migration costs and savings even for highly educated households,

$$
\bar{A} \bar{w} h(\bar{e}(\bar{A}))-A_{t} \bar{w} h\left(\bar{e}\left(A_{t}\right)\right) \leq(1+\bar{r})\left(F+\bar{e}(\bar{A})-\bar{e}\left(A_{t}\right)\right) .
$$

The No-migration regime is equivalent to the economy without labor mobility because migration is not profitable. The economy is at a high technological level and households do not benefit from migration. We will not consider this case in the remainder of the study since we are interested in the effects of migration.

1. High-migration regime.

This case corresponds to countries with a low productivity level and/or with very low migration costs. The optimal choices of households depend on the inherited wealth of the household. The function $\Phi$ determines the optimal migration level. Because the poorest households profit from migration, the slope is positive in its linear part. Hence, the maximum of $\Phi$ is $\min \left\{b_{t}^{i} / F, 1\right\}$ if the maximum lies in the linear part. If the maximum lies in the strictly concave part, the maximum satisfies $\Phi^{\prime}\left(m_{t}^{i} \mid b_{t}^{i}\right)=0$ (or $m_{t}^{i}=0$ if $\Phi^{\prime}\left(m_{t}^{i} \mid b_{t}^{i}\right) \neq 0$, for all $m_{t}^{i} \in\left[0,\left(b_{t}^{i}-e_{0}\right) / F\right]$ ).

\footnotetext{
${ }^{16}$ Note that the investment in education increases with wealth. If we use the Implicit Function Theorem we obtain

$$
\frac{\partial \phi_{e}\left(b_{t}^{i}\right)}{\partial b_{t}^{i}}=\frac{\eta}{(1-\eta)} \frac{\left(e_{t}^{i}-e_{0}\right)^{\eta}}{h\left(e_{t}^{i}\right)}=\frac{\eta}{(1-\eta)} \frac{h\left(e_{t}^{i}\right)-\mu}{h\left(e_{t}^{i}\right)}>0 .
$$
}


In the high-migration regime we can distinguish two subcases. As can be seen in Figure 6 there can be a bequest level that has two maximums. We assume that in this case households prefer to send the smallest share possible to the destination country. This bequest level determines the minimum amount $\underline{e}\left(\bar{A}-A_{t}\right)$ invested in education. However, it could also be the case that the technological gap is so high that households want to migrate as much as possible, i.e., the maximum is $\min \left\{b_{t}^{i} / F, 1\right\}$. In this case, households always prefer to migrate than to become educated because the opportunities in their country are too low compared with the destination country. We assume that migration costs $F$ are high enough as to ensure that not all the households prefer to migrate before they become educated.

Households' choices can be summarized as follows:

a. If $b_{t}^{i} \leq \underline{e}\left(\bar{A}-A_{t}\right)$, then $m_{t}^{i}=b_{t}^{i} / F, e_{t}^{i}=0$, and $s_{t}^{i}=0$.

The poorest households do not save and invest all their wealth in migration.

b. If $\underline{e}\left(\bar{A}-A_{t}\right)<b_{t}^{i}<\bar{e}\left(\bar{A}-A_{t}\right)+F$ then $m_{t}^{i}=\phi_{m}\left(b_{t}^{i}\right)=\left(b_{t}^{i}-\phi_{e}\left(b_{t}^{i}\right)\right) / F, e_{t}^{i}=\phi_{e}\left(b_{t}^{i}\right)$, and $s_{t}^{i}=0$.

If the wealth of the household is high enough, households choose the optimal combination of education and migration in relation to their wealth. However, as they cannot afford the optimal level of education and entirely migrate, they do not save and invest all their wealth in education and migration.

c. If $b_{t}^{i} \geq \bar{e}\left(\bar{A}-A_{t}\right)+F$ then $m_{t}^{i}=1, e_{t}^{i}=\bar{e}(\bar{A})$, and $s_{t}^{i}=b_{t}^{i}-\bar{e}(\bar{A})-F$.

This case is for the unconstrained households who can choose the optimal level of education, migrate and still have some wealth to be saved.

Poor households invest all their wealth in migration. If the returns on education are higher than the returns on migration, the migration share falls and households start to invest in education. In the case of education being profitable, both education and the share of migration increase with wealth until households achieve their maximum optimal values. Then, households start saving.

2. Low-migration regime.

This case corresponds to countries with a high productivity level and high migration costs. In this case, only the households that are wealthy enough profit from migration. The poorest households do not migrate and save their endowments. The home technology determines the minimum education level. In this case, the slope of the linear part in the $\Phi$ function is negative, which prevents households from migrating unless they are educated.

Households' optimal decisions are the following:

a. If $b_{t}^{i} \leq \underline{e}\left(\bar{A}-A_{t}\right)$, then $s_{t}^{i}=b_{t}^{i}, e_{t}^{i}=0$, and $m_{t}^{i}=0$.

This is the case with the poorest households. If the wealth of the household is not high enough for it to be profitable to become educated or migrate, these households invest all their wealth in savings. 
b. If $\underline{e}\left(\bar{A}-A_{t}\right)<b_{t}^{i}<\bar{e}\left(\bar{A}-A_{t}\right)+F$, then $s_{t}^{i}=0, e_{t}^{i}=\phi_{e}\left(b_{t}^{i}\right)$, and $m_{t}^{i}=\phi_{m}\left(b_{t}^{i}\right)$.

If the wealth of the household is high enough, households choose the optimal combination of education and migration in relation to their wealth. There will be households that choose to become educated and do not migrate. As they cannot afford the optimal level of education and entirely migrate, they do not save and invest all their wealth in education and migration.

c. If $b_{t}^{i} \geq \bar{e}\left(\bar{A}-A_{t}\right)+F$ then $e_{t}^{i}=\bar{e}(\bar{A}), s_{t}^{i}=b_{t}^{i}-\bar{e}(\bar{A})-F$, and $m_{t}^{i}=1$.

This case is for the unconstrained households who can choose the optimal level of education, migrate and still have some wealth to be saved.

We have observed that, if households invest in education and migration, the investment in education and the share of the household that migrates increase as the inherited wealth increases.

The following proposition summarizes the evolution of migration rates.

Proposition 3. In an economy with international labor mobility,

(i) migration is profitable if the technological gap to migration costs ratio $\left(\bar{A}-A_{t}\right) / F$ is high enough;

(ii) if the technological gap to migration costs ratio is low, only wealthy and highly educated households migrate and the migration share $m_{t}$ increases with wealth;

(iii) if the technological gap to migration costs ratio is high, the migration share of uneducated households does not decrease with wealth unless the household becomes educated. If the household is educated, migration and education increase with wealth.

Proof. It follows from the optimal decisions of households above.

This proposition characterizes the size and selection of migrants according to their level of education, and states that size and selection depend on the technological gap to migration costs ratio. Countries characterized by a low ratio select individuals with high skills to migrate, and countries characterized by a high ratio select individuals with high and low skills. Figure 7 illustrates the shape of selection and size of migration for different migration costs and a fixed technological gap in a given period. The gray color depicts a situation of high migration costs and, therefore, there is only migration of the highly skilled. The horizontal lines correspond to medium migration costs and migration increases as skills increase. Meanwhile, the dotes depict low migration costs and, therefore, migration is higher for the low and highly skilled than for the medium skilled. ${ }^{17}$

From the households' optimal decisions we can obtain aggregate migration rates. For fixed migration costs, if the technological gap is reduced, less households benefit from migration, therefore, migration rates become lower. Similarly, for a fixed technological

\footnotetext{
${ }^{17}$ The gray color is named J-shape in the empirical part, the horizontal lines I-shape, and the dots U-shape.
} 
Figure 7 Migrant Size and Selection for a fixed technological gap and different migration costs.

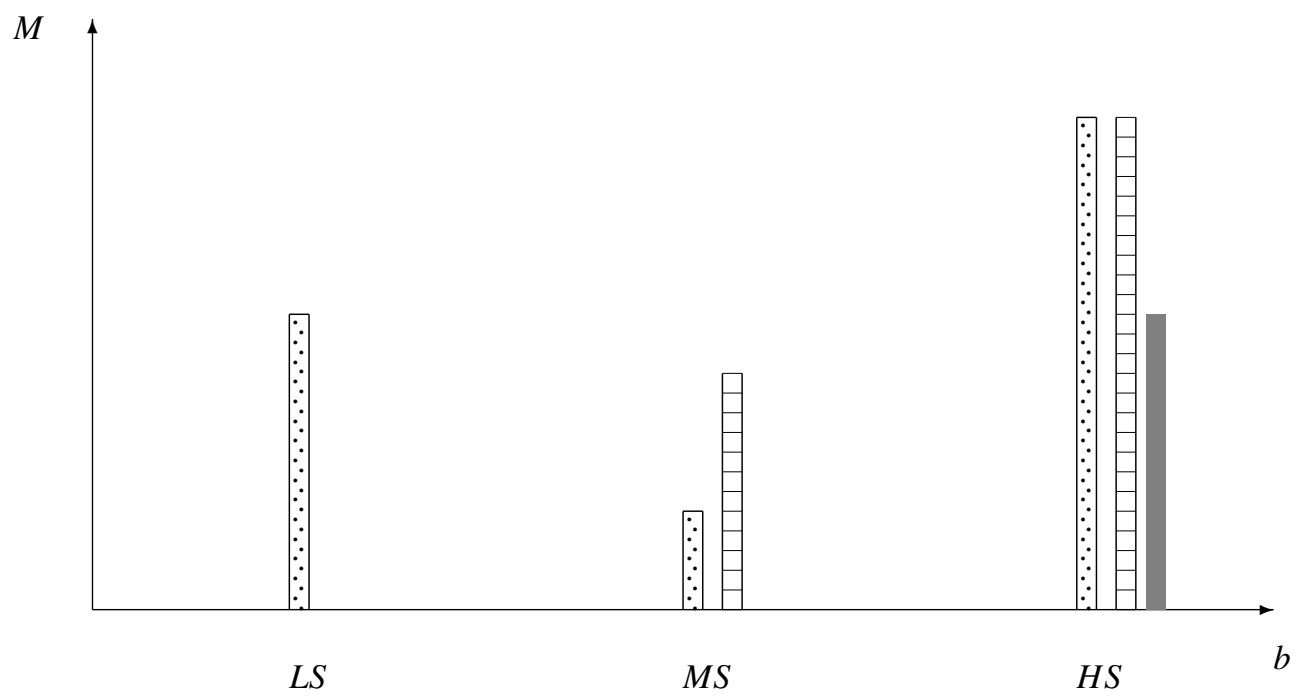

level, a reduction in migration costs increases the amount of households that can benefit from migration and increases the aggregate rate of migration. The following corollary summarizes the results.

Corollary 1. Aggregate migration rates decline if the technological process reduces the technological gap for given migration costs $F$. Moreover, a reduction in migration costs increases aggregate migration rates for a given technological gap $\bar{A}-A_{t}$.

Proof. Let $P$ be the technological gap to migration costs ratio $\left(\bar{A}-A_{t}\right) / F$. The result follows from the fact that $\phi_{m}\left(b_{t}^{i}, P_{1}\right) \leq \phi_{m}\left(b_{t}^{i}, P_{2}\right)$ if and only if $P_{1} \geq P_{2}$.

The migration literature emphasizes the role of past migration as a way of reducing migration costs through networks. A reduction in migration costs changes the ratio that determines the size and the individuals who decide to migrate, higher migration reduces the ratio of high to low skilled migrants (Docquier et al. 2010). In our model, a reduction in migration costs can change countries from Low- to High-migration regimes. Hence, a reduction in migration costs in our model can explain why some countries change their pattern in the selection of migrants, countries with a high technological level close to the technology frontier can be in the high ratio due to a reduction in migration costs. A change from Low- to High-migration regime reduces the rate of high to low skilled migrants.

\subsubsection{The evolution of wealth and income in an economy with international labor mobility}

As in the economy without migration, the evolution of bequests determines the evolution of the dynasty's wealth. The possibility of migration generating an extra source of income can 
modify the evolution of bequests. In the economy without migration we can characterize the dynamics of bequests as a function of inherited wealth and the level of technology. In this case, we also take into account the level of technology in the destination country and the migration costs.

For the High- and Low-migration regimes, the wealth dynamics are given by:

$$
b_{t+1}^{i}=\psi\left(b_{t}^{i} ; A_{t}, \bar{A}, F\right)= \begin{cases}\frac{\gamma}{1+\gamma}\left(W\left(b_{t}^{i}\right)+R\left(b_{t}^{i}\right)\right) & \text { if } b_{t}^{i} \leq \underline{e}\left(\bar{A}-A_{t}\right) \\ \frac{\gamma}{1+\gamma} W\left(b_{t}^{i}\right) & \text { if } \underline{e}\left(\bar{A}-A_{t}\right)<b_{t}^{i}<\bar{e}\left(\bar{A}-A_{t}\right)+F \\ \frac{\gamma}{1+\gamma}\left(W\left(b_{t}^{i}\right)+R\left(b_{t}^{i}\right)\right) & \text { if } b_{t}^{i} \geq \bar{e}\left(\bar{A}-A_{t}\right)+F,\end{cases}
$$

where

$$
W\left(b_{t}^{i}\right)=\left(A_{t}+\left(\bar{A}-A_{t}\right) \phi_{m}\left(b_{t}^{i}\right)\right) \bar{w}\left(\mu+\left(\phi_{e}\left(b_{t}^{i}\right)-e_{0}\right)^{\eta}\right)
$$

is labor income and

$$
R\left(b_{t}^{i}\right)=\left(b_{t}^{i}-\phi_{m}\left(b_{t}^{i}\right) F-\phi_{e}\left(b_{t}^{i}\right)\right)(1+\bar{r})
$$

is capital income.

In the economy without migration, given a technological level, the initial distribution of wealth characterizes the long-run distribution of wealth. If the dynamics of bequests display three steady states, the long-run distribution is polarized, whereas if the dynamics of bequests display a single steady state, the long-run distribution converges to a single point. Thus, there are two different wealth distribution patterns in the long run that depend on the technological level.

In the economy without migration, $\widehat{A}$ is the threshold level of technology that determines whether the dynamical system $b_{t+1}^{i}=\psi\left(b_{t}^{i}, A\right)$ has one or two stable steady states. Let $\widehat{A}_{m}$ be the threshold technology that determines whether the dynamical system $b_{t+1}^{i}=\psi\left(b_{t}^{i}, A, \bar{A}, F\right)$ has one or two stable steady states.

Figure 8 compares the evolution of bequests in an economy with a low productivity level, i.e., the dynamical system displays two stable steady-state points. The function $\psi\left(b_{t}, A_{l}, \bar{A}, \infty\right)$ shows the evolution without migration while the others show the evolution with migration. Two different migration regimes are presented, High-migration regime on the left side and Low-migration regime on the right. As we can observe, migration is profitable for all households in the High-migration regime whereas it is only profitable for educated households in the Low-migration regime. Thus, bequests left to children increase in the presence of migration as long as it is profitable. Since the productivity level is equal in both scenarios $\left(\psi\left(b_{t}, A_{l}, \bar{A}, \infty\right)\right.$ is the same) what determines whether the economy is in the High- or Low-migration regime are the migration costs. Lower migration costs are related to the High-migration regime. Moreover, within the High-migration regime $\psi\left(b_{t}, A_{l}, \bar{A}\right.$, Low $)$ shows lower migration costs than the costs of $\psi\left(b_{t}, A_{l}, \bar{A}\right.$, High $) .{ }^{18}$

\footnotetext{
${ }^{18}$ Galor and Tsiddon (1997) use a numerical example to illustrate the evolution in the dynamical system that relates parents and children's human capital. This example presents diminishing complementarity be-
} 
Figure 8 Comparison of the evolution of bequests across dynasties.
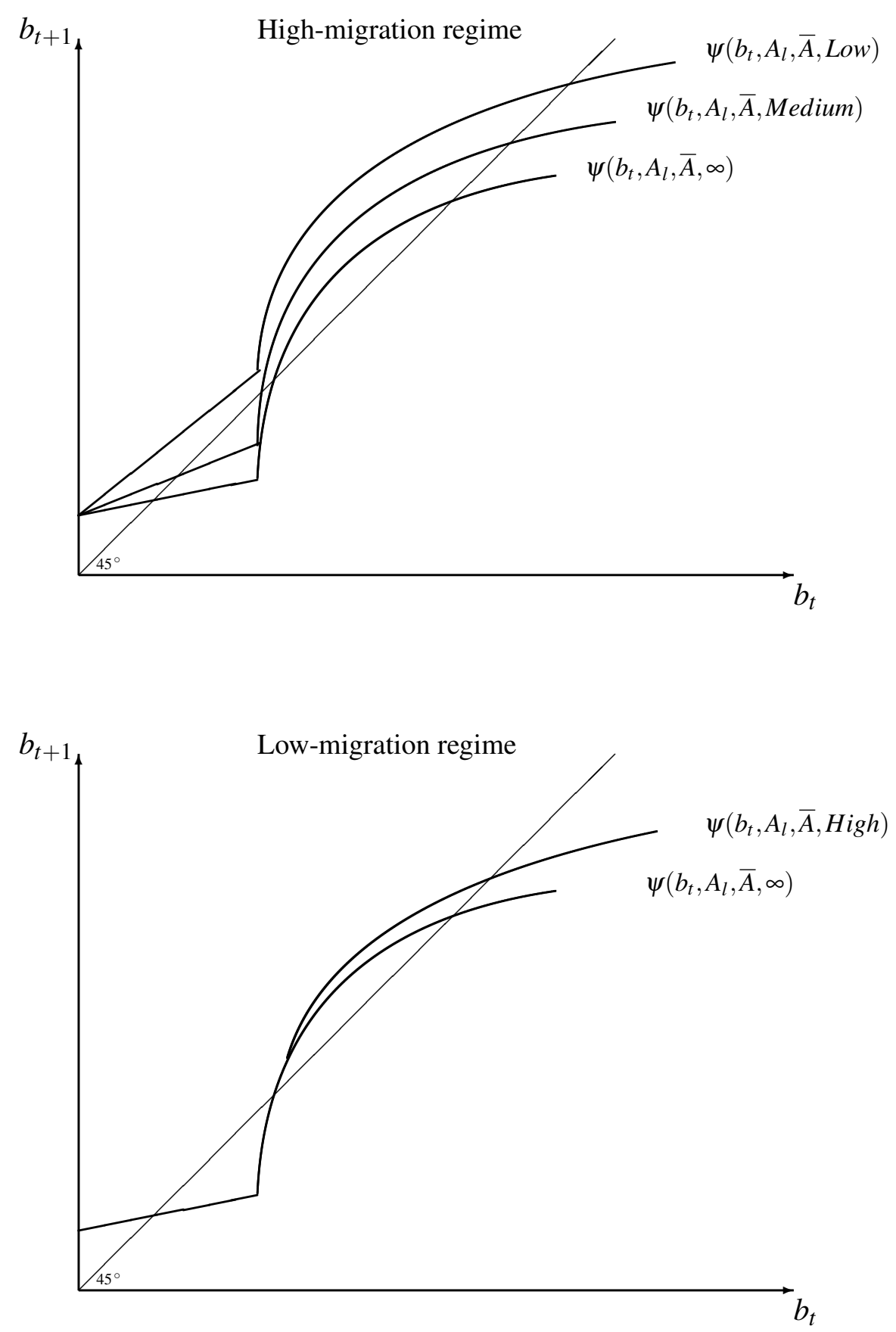
Figure 9 Comparison of the evolution of bequests across dynasties.

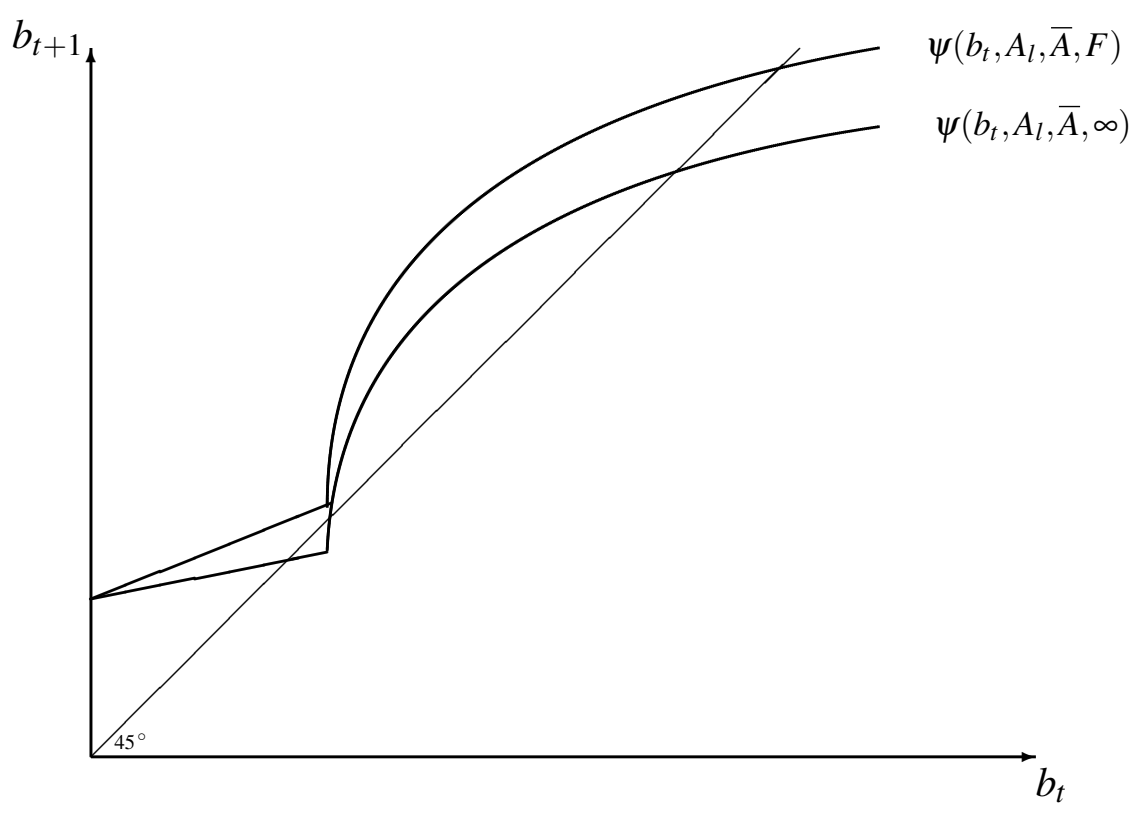

We have observed that the economy without access to migration converges to a polarized or equally distributed economy. We have also found that with access to migration the distribution of bequests within a dynasty changes. These changes affect the wealth and income distributions in the short and long run. The higher amount of bequests left to the next generation generates higher inequality in the distribution of wealth and income. Nevertheless, this higher amount reduces the technological threshold necessary to reduce polarization as shown in Figure 9. As in the economy without migration, we observe that in time periods in which the dynamical system $b_{t+1}^{i}=\psi\left(b_{t}^{i}, A_{t}, \bar{A}, F\right)$ displays multiple steady-state equilibria, the distribution of wealth and income gravitates towards increased polarization, whereas in periods in which the dynamical system displays a single globally stable steady-state equilibrium the distributions of wealth and income gravitates towards diminished polarization.

Proposition 4. In an economy with international labor mobility, the following holds:

(i) Inequality increases over time in countries with low technological levels and high migration costs.

(ii) Inequality decreases over time in countries with high technological levels or low migration costs.

tween resources invested and parents' human capital. In our scenario, diminishing migration costs due to past migration leads to a similar type of movement in the dynamical system of bequests. 
(iii) Migration reduces the technological level that determines whether the economy increases or decreases economic inequality.

Proof. Part (i) follows from Figure 8. Part (ii) follows from Proposition 2 and Figure 8. Part (iii) follows from Figure 8.

\section{Conclusion}

This paper establishes a theoretical relation between economic inequality and migration in labor-exporting countries. It can thus provide an explanation for the evolution of inequality in countries with different productivity levels. It is shown that the effect of migration on inequality, through remittances and bequests left to children, depends on the productivity differences and the migration costs between source and destination countries of migrants.

On the one hand, the model includes the main drivers of migration such as education decisions. We are able to characterize the share of population that migrates (size) and the education characteristics of migrants (selection) consistently with previous studies and data. On the other hand, the dynamic part permits study of the long-term effects of migration on inequality in source countries. Following Kuznets' classic view of the relation between development and inequality, we have augmented this view by using migration as a possible source of variation in this relation. Countries with an equal level of development can show different levels of inequality due to different migration opportunities.

The model predicts that in countries with a low level of technology or countries with a high technological gap with respect to developed countries, the benefits of migration are higher but economic inequality increases unless the migration costs are very low. All households in the economy can benefit from migration but the wealthiest households can benefit more, and this results in an increasing difference in wealth across households. In contrast, more developed countries experience a reduction in inequality, but only highlyeducated households can benefit from migration unless the migration costs are very low.

Some studies reveal the benefits of migration and remittances on growth. Since migrants increase wealth in our model, we take this wealth effect to study the impact on inequality. We have shown that migration and remittances reduce the productivity level necessary to reduce inequality compared to an economy without migration. In line with Kuznets' hypothesis, we depart from the baseline model that predicts that developing countries increase inequality and developed countries reduce inequality to show that migration can be a factor that accelerates this process. Migration helps and encourages households to accumulate wealth and invest in education in order to acquire human capital in migrants' homes.

Our analysis disregards several important features. For example, it does not include either brain drain or brain gain effects in a stochastic sense even though migration increases human capital in source countries in the model. Brain drain and brain gain can affect the technological process and the accumulation of human capital by decreasing or increasing 
in amount. Moreover, our analysis only considers the network effects of migrants in a vague sense. In line with the empirical literature, we could consider migration costs as a decreasing function of aggregate past migration. The introduction of decreasing costs would not change the main conclusions of the paper but convergence to an egalitarian society would be faster. As we have observed, lower migration costs increase the amount of people who can benefit from migration. Furthermore, a reduction in migration costs yields a reduction in the level of development necessary to reduce inequality.

\section{References}

[1] Barro, R.J., 2000. "Inequality and Growth in a Panel of Countries", Journal of Economic Growth. Vol. 5, pp. 5-32.

[2] Beine, M., Docquier, F., Ozden, C., 2011. "Diasporas", Journal of Development Economics, Vol. 95(1), pp. 30-41.

[3] Bollard, A., McKenzie, D., Morten, M., Rapoport, H., 2011. "Remittances and the Brain Drain Revisited: The microdata show that more educated migrants remit more", World Bank Economic Review. Vol. 25(1), pp. 132-156.

[4] Borjas, G.J., 1987. "Self-Selection and the Earnings of Immigrants", American Economic Review. Vol. 77(4), pp. 531-553.

[5] Borjas, G.J., 2003. "The Labor Demand Curve Is Downward Sloping: Reexamining the Impact of Immigration on the Labor Market", Quarterly Journal of Economics. Vol. 118(4), pp. 1335-74.

[6] Caponi, V., 2010. "Heterogeneous Human Capital and Migration: Who Migrates from Mexico to the US?", Annales d'Economie et de Statistique, Issue 97-98, pp. 207-234.

[7] Ceroni, B., 2001. "Poverty Traps and Human Capital Accumulation”, Economica. Vol. 68, pp. 203-19.

[8] Docquier, F., Lowell, B.L., Marfouk, A., 2009. "A gendered assessment of highly skilled emigration”, Population and Development Review. Vol. 35(2), pp. 297321.

[9] Docquier, F., Rapoport, H., Shen, I., 2010. "Remittances and inequality: A dynamic migration model”, Journal of Economic Inequality. Vol. 8(2), pp. 197-220.

[10] Fernández-Huertas Moraga, J., 2013. "Understanding Different Migrant Selection Patterns in Rural and Urban Mexico", Journal of Development Economics. Vol. 103(C), pp. 182-201.

[11] Friedberg, R., Hunt, J., 1995. "The Impact of Immigrants on Host Country Wages, Employment and Growth", Journal of Economic Perspectives. Vol. 9(2), pp. 23-44. 
[12] Galor, O., Tsiddon, D., 1997. "The Distribution of Human Capital and Economic Growth", Journal of Economic Growth. Vol. 2(1), pp. 93124.

[13] Galor, O., Zeira, J., 1993. "Income Distribution and Macroeconomics", Review of Economic Studies. Vol. 60, pp. 3552.

[14] Grogger, J., Hanson, G., 2011. "Income Maximization and the Selection and Sorting of International Migrants", Journal of Development Economics. Vol. 95(1), pp. 42-57.

[15] Ha, W., Yi, J., Zhang, J., 2009. "Inequality and Internal Migration in China: Evidence from Village Panel Data". Human Development Research Paper, United Nations Development Programme.

[16] Hanson, G., 2010. "International Migration and Development", Equity and Growth in a Globalizing World (eds. Ravi Kanbur and Michael Spence). Chapter 10, pp. 229262. Commission on Growth and Development, The World Bank.

[17] Kuznets, S., 1955. "Economic Growth and Income Inequality", American Economic Review.Vol. 45(1), pp. 1-28.

[18] Lucas, R., Sark, O., 1985. "Motivations to remit: evidence from Botswana", Journal of Political Economy. Vol. 93, pp. 901-918.

[19] Mayda, A., 2010. "International migration: a panel data analysis of the determinants of bilateral flows", Journal of Population Economics. Vol. 23(4), pp. 1249-1274

[20] Mckenzie, D., Rapoport, H., 2007. "Network effects and the dynamics of migration and inequality: Theory and evidence from Mexico", Journal of Development Economics. Vol. 84, pp. 1-24.

[21] Ottaviano, G., Peri, G., 2012. "Rethinking the Effects of Immigration on Wages", Journal of the European Economic Association. Vol. 10(1), pp. 152197.

[22] Quah, D., 2003. "One third of the world's growth and inequality", Inequality and Growth: Theory and Policy Implications (eds. Theo Eicher and Stephen J. Turnovsky). Chapter 2, pp. 27-58. MIT Press, Cambridge.

[23] Stark, O., Taylor, J.E., Yitzaki, S., 1986. "Remittances and Inequality”, The Economic Journal. Vol. 96(383), pp. 722-740.

[24] Vidal, J., 1998. "The effect of emigration on human capital formation", Journal of Population Economics. Vol. 11(4), pp. 1432-1475. 


\section{Appendix}

In Figure 10 we can observe the distribution of migration shapes around the world. In the figure, J-shaped countries are colored in gray, I-shaped countries have horizontal lines, and U-shaped countries have dots. In addition, these shapes are highly persistent over time, there are only a few countries that change their shapes between 1990 and 2000. In 1990 there were 86, 61 and 43 out of 190 countries with U-, I- and J-shape respectively. In 2000 there were 83,69 , and 37 out of 189 . We exclude the 8 countries that present a different pattern. In fact, 146 countries out of 188 maintain the shape, 16 change from J to I (Bosnia and Herzegovina, Cambodia, Central African Republic, Chile, Indonesia, Kiribati, Laos, Liberia, Malawi, Mali, Marshall Islands, Federated States of Micronesia, Seychelles, Sierra Leone, Solomon Islands, and Zimbabwe), 10 countries from J to U (Australia, Azerbaijan, Cyprus, Estonia, Georgia, Latvia, Moldova, Monaco, Spain, and Uzbekistan), 7 from / to J (Egypt, Jordan, New Zealand, Pakistan, Qatar, Saudi Arabia, and United Arab Emirates), 4 from J to U (Croatia, Cuba, Italy, and Sweden), 2 from U to I (France, Switzerland), and 2 from I to U (Liechtenstein and San Marino).

Figure 10 Migrant selection shapes in 1990.
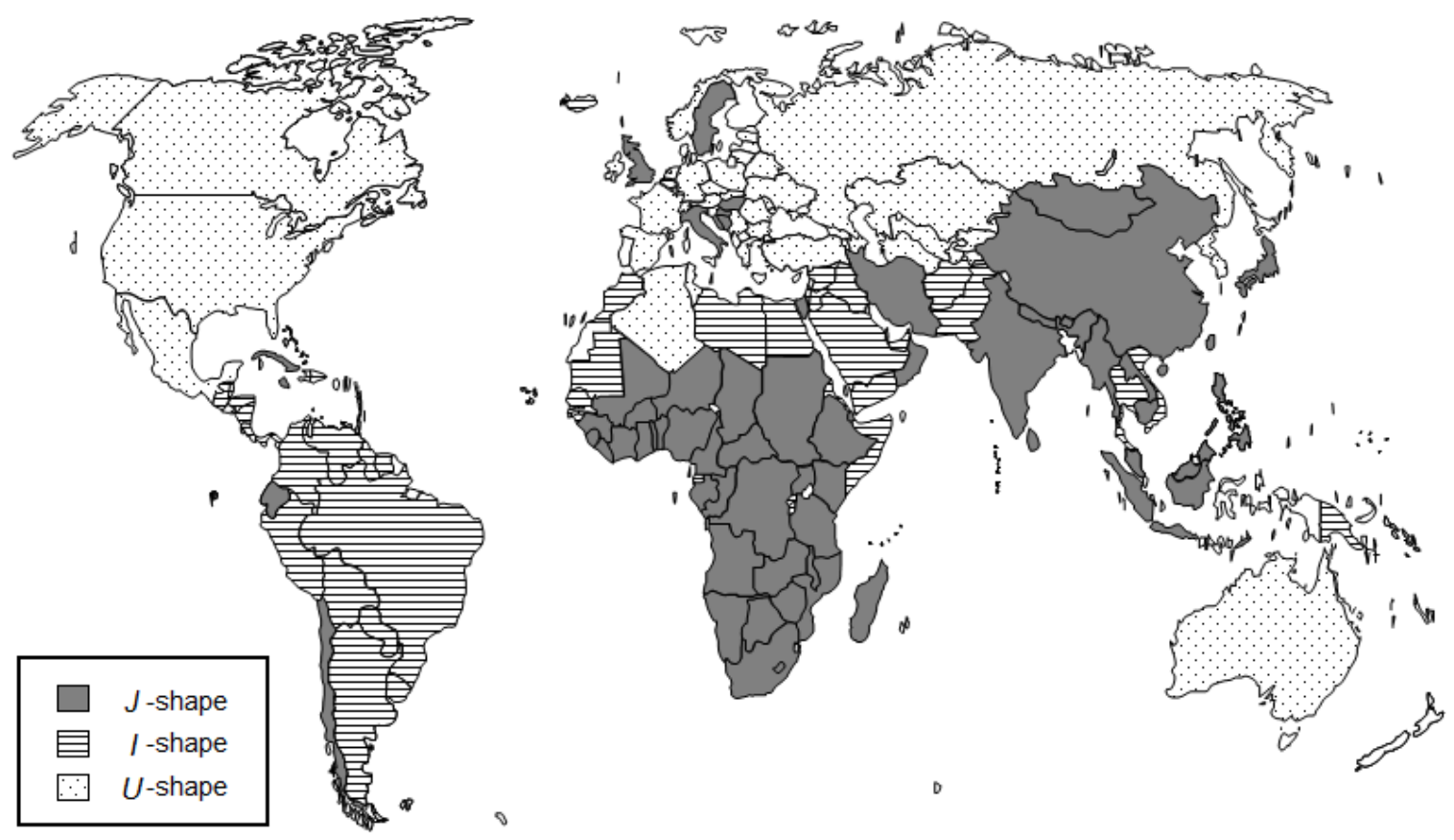